\title{
Prosthodontic Rehabilitation of Missing Dentition Using Multi Unit Precision Attachment Hybrid Overdentures-Clinical Report of Two Patients
}

\author{
Hariharan Ramakrishnan* \\ Professor, Department of Prosthodontics \& Implantology, Ragas Dental College \&Hospital, Chennai, India
}

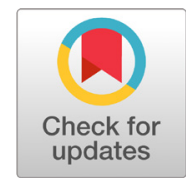

*Corresponding author: Hariharan Ramakrishnan, Professor, Department of Prosthodontics \& Implantology, Ragas Dental College \&Hospital, Uthandi, Chennai, India.

Received Date: October 28, 2020

Published Date: November 10, 2020

\begin{abstract}
Prosthodontic rehabilitation of a patient with terminal dentition is very challenging. Any conservative treatment that can delay or eliminate future prosthodontic problems should be considered. Complete and partially edentulous patients are generally unsatisfied due to the inherent instability of dentures during functional and parafunctional movements which results due to the lack of adequate supporting hard and soft tissues. Inspite of rapid development and good success rate in the field of implantology, preservation of remaining natural teeth or roots is more desirable which supports Devan's dictum. Overdenture is a complete or partial denture prosthesis supported partly by soft tissues and partly by retained natural teeth or its roots or implants.

Overdenture increases the retention, stability and support, improves the masticatory efficiency, preserves the alveolar bone and muscular patterns and preserves sensory receptors within the periodontal ligament which increases manipulative skills in handling the denture. Retention and stability of overdentures can be improved by attachments or magnets. Fixed partial denture is not an option when there is no distal abutment. The solution of such a critical situation is to give combined or hybrid prosthesis. A combined prosthesis carries the advantage of fixed removable prostheses without surgical intervention, where an acrylic prosthesis is retained with an extra coronal attachment to tooth. This paper presents a twin patient report of rehabilitation of a mandibular and maxillary terminal dentition with a combined prostheses of acrylic retained by extra coronal precision attachment system (Rhein 83, Italy).
\end{abstract}

Keywords: Case report; Overdentures; Precision attachment; Combined prosthesis; Fixed-removable; Extra coronal attachment

\section{Introduction}

Prosthetic rehabilitation always aims to fulfill the esthetics and functions and it should not fail to concentrate on preservation. Challenges for restoration such as bone loss, terminal tooth loss arise due to duration of edentulousness, pattern of tooth loss, size of deformity that requires careful attention and meticulous treatment planning. More of these challenges are encountered in the act of accomplishing the patient preference who demands fixed prosthesis as a treatment option. Even though fixed prosthesis can give comfort and psychological benefit to the patient [1]. Depending upon the factors like bone loss, edentulous area and cost, treatment opin ion from the dentist aspect will change. Common fixed treatment options include implant supported fixed prosthesis, over denture, combined fixed and removable prosthesis retained with precision attachments [2].

Rehabilitation of complete and partially edentulous arch can be challenging when it is a distal extension situation classified under Kennedy's class I and class II situations [3]. Precision attachment denture combines fixed and removable prosthodontics in such a way as to create most aesthetic partial denture possible. It consists of 2 components- matrix and patrix where matrix component is inserted into fixed prosthesis and patrix component into removable 
acrylic partial denture [2]. Fixed partial denture is not in option as there is no distal abutment. The solution of such a critical situation is to give combined prosthesis [4]. A combined prosthesis carries the advantage of fixed prostheses without surgical intervention, where a removable prosthesis is retained with an extra coronal attachment to tooth or implant [5-7]. In this article we will be discussing two patient reports which provided a satisfactory and successful prosthetic rehabilitation by restoring function, esthetics and comfort to the patient using Rhein 83 (pre-fabricated) attachment prosthesis.

\section{Case Report 1}

A 68-year-old male patient visited the department of Prosthodontics. There is no significant medical, family and psychosocial history. On intraoral examination, there is evidence of terminal dentition in both maxillary and mandibular arches 21, 22, 23 (Maxillary left central and lateral incisors and canines) are healthy in the maxillary arch and 43,44,45 (Mandibular right are healthy in the mandibular arch. Treatment options are explained. Diagnostic impressions are made with alginate (Algitex, DPI, India) and casts (Kalabhai, India) poured in dental stone. Facebow transfer is done (Hanau wide vue, USA) and diagnostic casts are mounted on semi adjustable articulator (Hanau wide vue, USA) using occlusal rims (Baseplate wax, India) sealed in centric relation of jaws and evaluated for all parameters. After all these clinical and radiographic examinations, we have arrived to a treatment plan of restoring with combined prosthesis. Patient consent for the same obtained.

Root canal treatment is done for all of the remaining teeth with post space being prepared (Gates Glidden drill, Premier dental, USA) to provide space for the dowel to be inserted as part of combination prosthesis. Dome shaped teeth preparation is done with $1.5 \mathrm{~mm}$ of axial walls close to surrounding gingiva. The external surfaces was prepared to receive over denture copings .Addition silicone light body material (Flexceed, GC, Japan)is injected in and around the root canal with the help of a delivery tips ( Pinkblue, India) and Plastic pivots(Rhein 83, Italy), (Figure 1), coated with tray adhesive (GC, Japan) on the external surface are inserted into the root canals simultaneously and a pick up one stage full arch impressions of maxilla and mandible are made with putty addition silicone impression material ( Flexceed putty, GC, Japan), (Figure 2). Casts are poured with Type IV dental stone (Kalabhai ultra-rock die stone, India), (Figure 3).

Figure 1: Prefabricated Pivots.
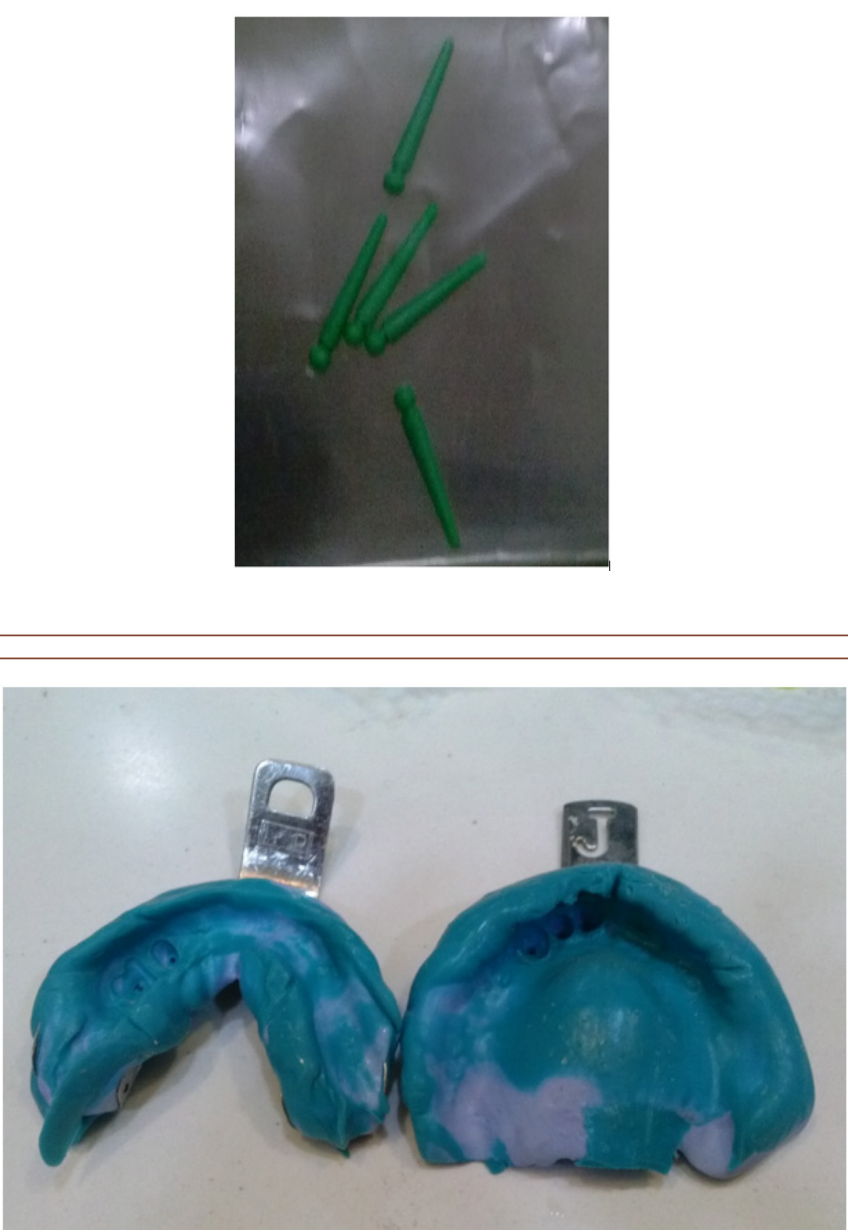

Figure 2: Master Impressions. 


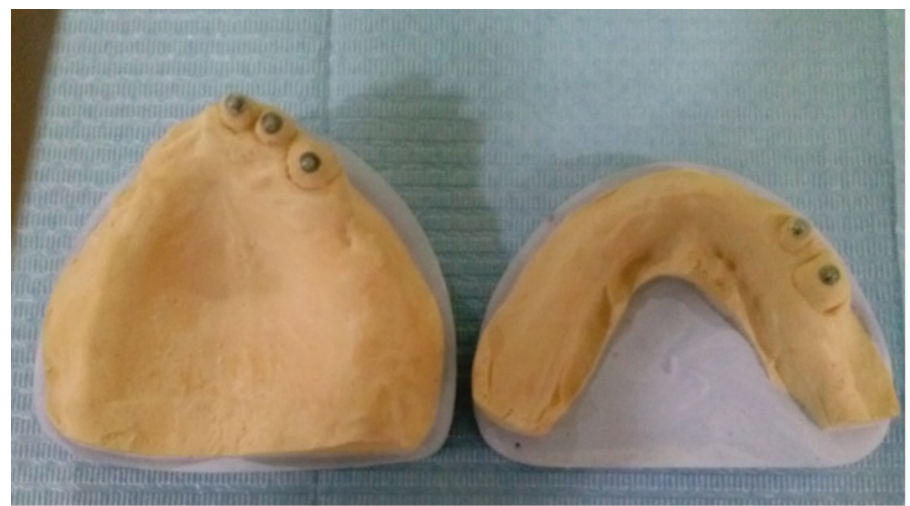

Figure 3: Master Casts

Surveying of the master casts is done to identify parallelism of copings to be cemented in future and also to identify path of insertion and removal of prosthesis. Individual wax copings (Pyrax, India) with custom dowel are fabricated in laboratory over the prepared natural teeth and cast in Chrome cobalt alloy (Form alloy, Indiamart). The castings (Figure 4) are tried in patient after trimming and polishing and they are picked up along with the retentive caps (Rhein 83, Italy) which was placed on the stud of copings ( Flexceed, GC, Japan) using one stage putty and light body addition silicone impression materials. Final Jaw relation is completed (Figure 5). Impression is sent to lab for fabrication of prosthesis along with semia djustable articulator. Teeth arrangement completed. (Acryrock, Indiamart) and try in is evaluated in the patient. The metal copings are cemented on to the prepared teeth first (Type 1, GIC cement, Japan). The final finished combined/hybrid prosthesis is tried in the patient and required occlusal corrections are done and final polishing carried out before insertion. (Figures 6-10) Cusp fossa occlusion is established. The patient is trained in wearing of the prosthesis and recalled after 24 hours for the necessary occlusal adjustments.

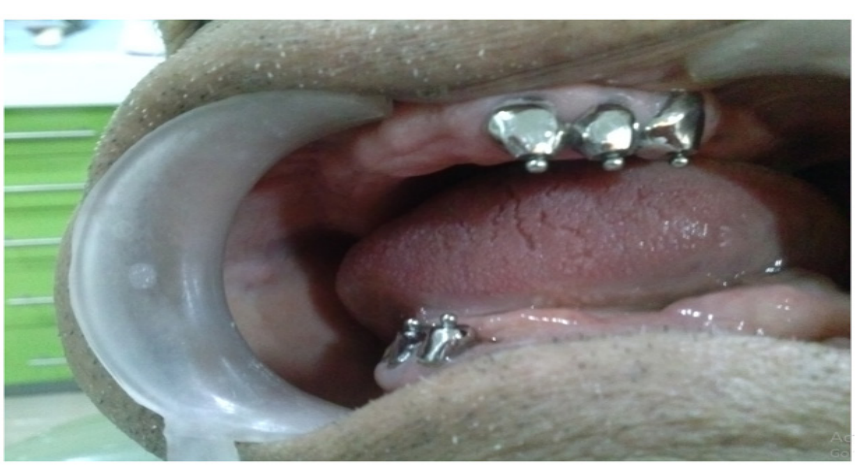

Figure 4: Metal Copings with Studs.

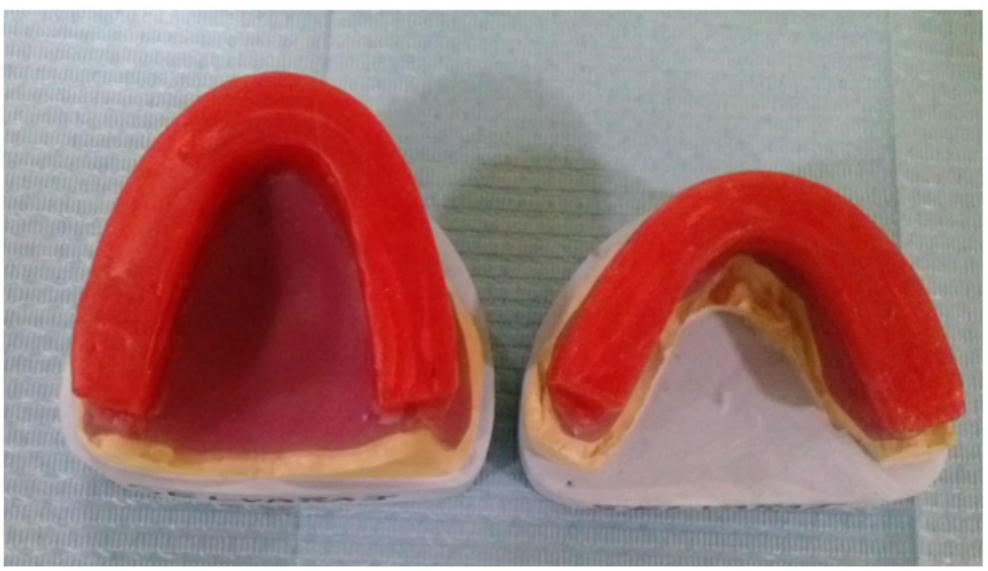

Figure 5: Occlusal Rims for Jaw Relations. 


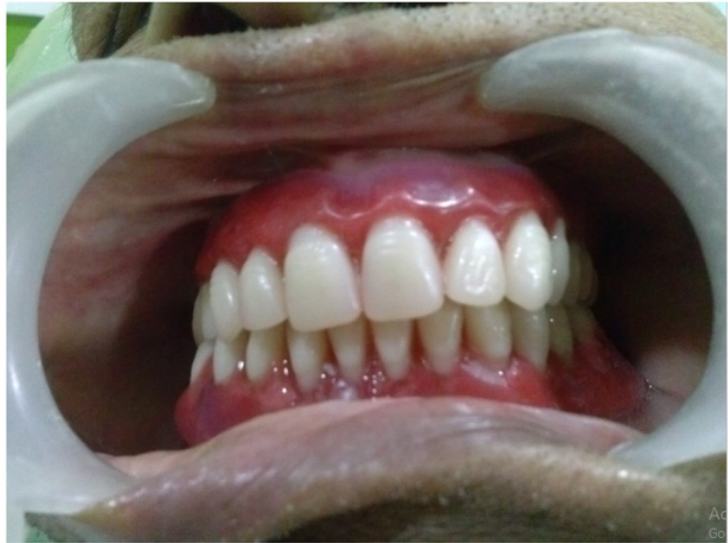

Figure 6: Try in of Teeth Arrangement.

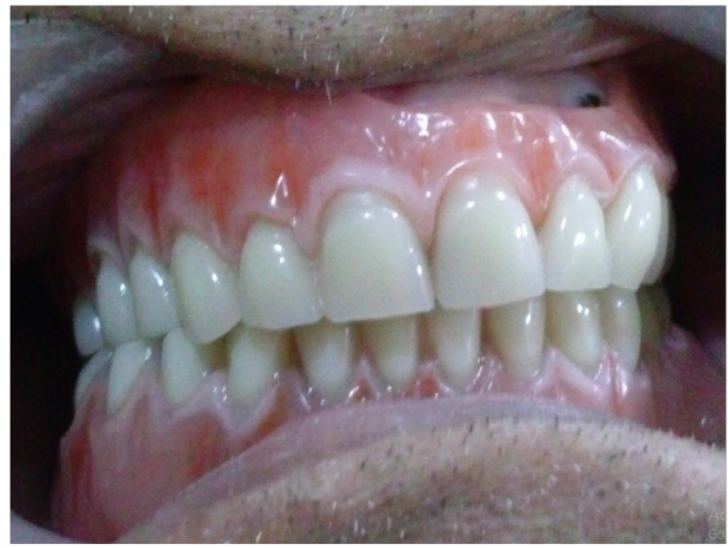

Figure 7: Overdenture Occlusion-Frontal View.

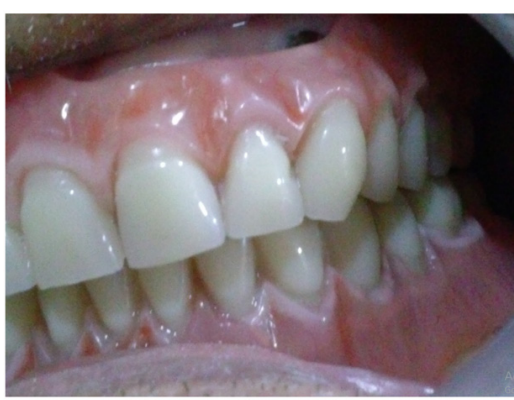

Figure 8: Overdenture Occlusion-Patient Right Side.

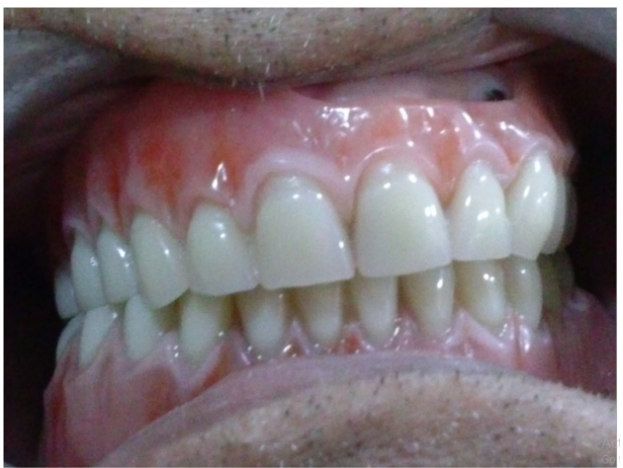

Figure 9: Overdenture Occlusion-Patient Left Side. 


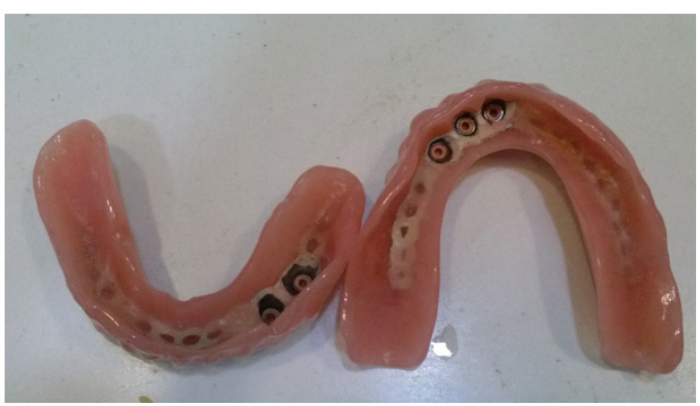

Figure 10: Final Dentures-Intaglio Surfaces.

\section{Case Report2}

A 62-year-old female patient came to the department of prosthodontics complaining of missing teeth and wants to replace it with fixed restoration. There is no significant medical, family, and psychosocial history. On intra oral examination, the teeth present in the maxillary arch are 15,13,12,11,21,22,23,26 (Maxillary right central, lateral, canine, second premolar, left central, lateral, canine, and first molar) and in the mandibular arch are 33,34,35 (mandibular left canine, first and second premolar) the patient had generalized caries in both maxillary and mandibular teeth and was sent to conservative dentistry department for restorations in all the carious teeth. Oral prophylaxis was carried out through scaling and polishing.

All the possible treatment options were explained, then fixed partial dentures in maxilla and precision attachment fixed removable prosthesis are planned in the mandible. Diagnostic impressions are made with alginate (Algitex, DPI, India). Diagnostic casts are poured with dental stone (Kalabhai, India). Facebow transfer (Hanau wide vue, USA) is done and tentative jaw relation is made. Then three mandibular teeth are root canal treated and post space is prepared. Maxillary teeth are prepared to receive a four unit fixed dental prosthesis in relation to $13,14,15$ and 16 as cantilever and four unit in relation to $23,24,25,26$. mandibular teeth are subjected to dome shaped preparation to receive metal copings with dowels.

Addition silicone impression material (Flexceed, light body, putty, GC, Japan) is injected in and around the root canal with the aid of plastic dispensing tips attached to material dispensing guns (Pinkblue, India). Plastic pivots (Rhein 83, Italy), coated with tray adhesive (GC, Japan) are inserted into the root canals and a pickup full arch impressions of the mandible is made (Figure 11). Casts are poured with Type IV dental stone (Kalabhai ultra-rock die stone, India) dental stone. Surveying of the master casts is done to identify the parellelism of the proposed copings and the prosthesis.

Individual wax copings (Pyrax, India) are fabricated and cast in chrome cobalt alloy (Form alloy, Indiamart). The castings (Figure 12) are tried in patient after trimming and polishing and are picked up along with the retentive caps (Rhein 83, Italy) which are placed on the stud of copings in the final one stage putty master impression. It is sent to lab for fabrication of prosthesis. Final jaw relations made. (Figure13,14). Teeth arrangement and subsequent try in, is evaluated in the patient (Figure 15). The metal copings are cemented on to the prepared teeth first (Type1, GIC cement, Japan). The final finished prosthesis is tried in the patient and required occlusal corrections are done and final polishing is done before insertion. The patient is trained in wearing of the prosthesis and recalled after 24 hours (Figures 16-20). The necessary adjustments are done.

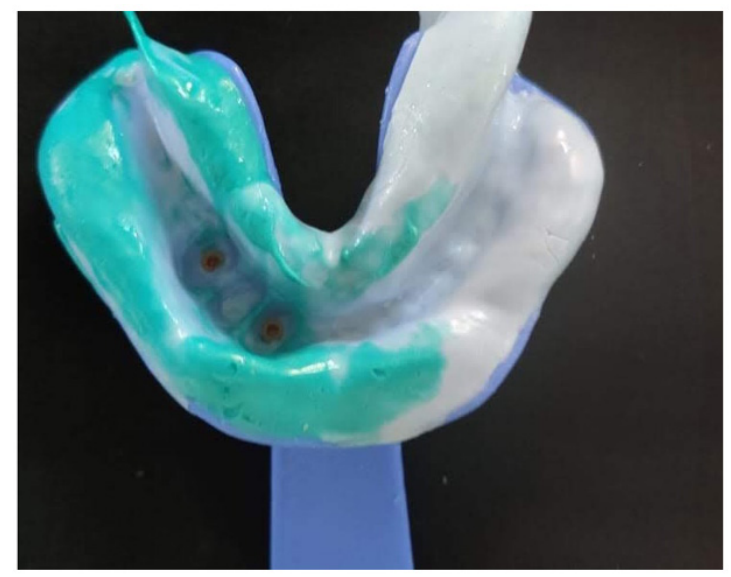

Figure 11: Master Impressions. 


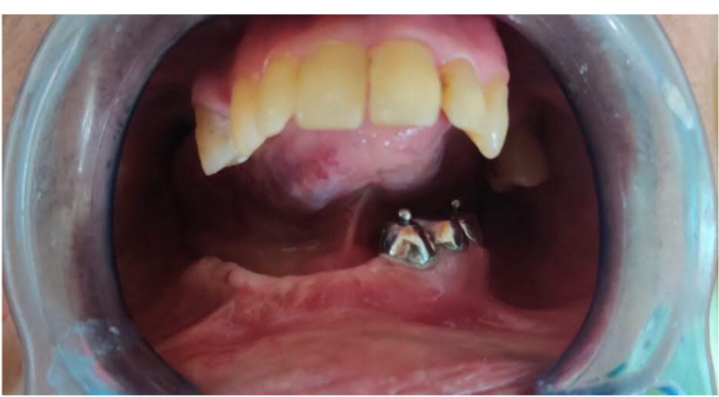

Figure 12: Metal Copings with Studs.

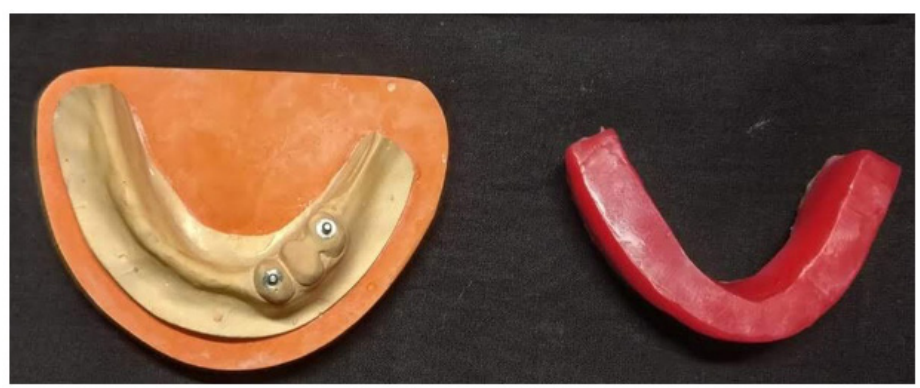

Figure 13: Master Cast and Occlusal Rims.

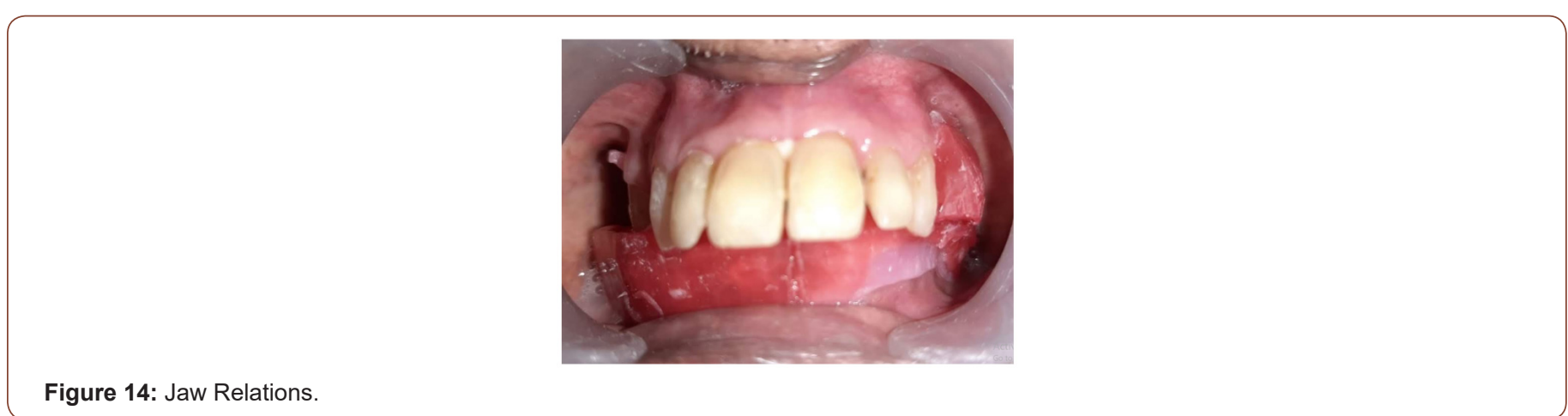

Figure 15: Try In.
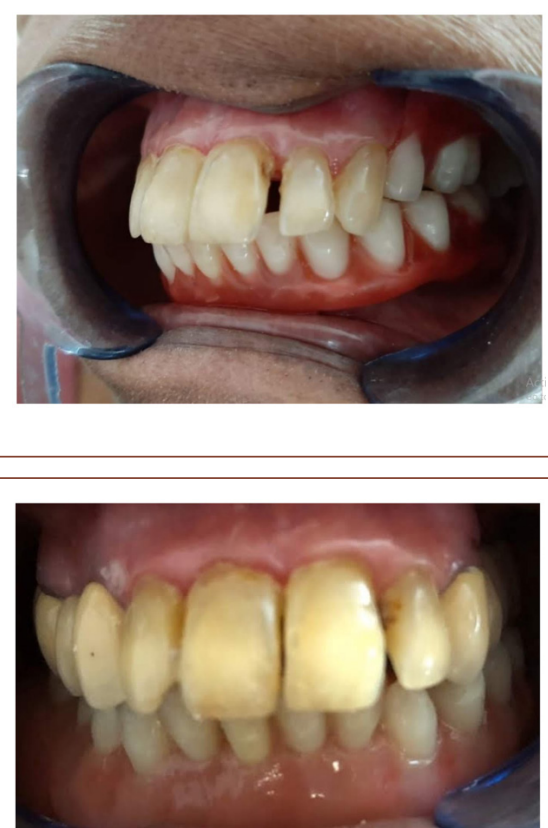

Figure 16: Final Mandibular Prosthesis-Frontal View. 


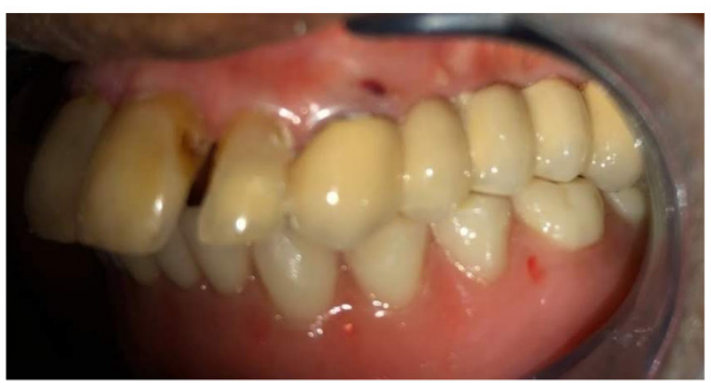

Figure 17: Final Mandibular Prosthesis-Patient Left Lateral.

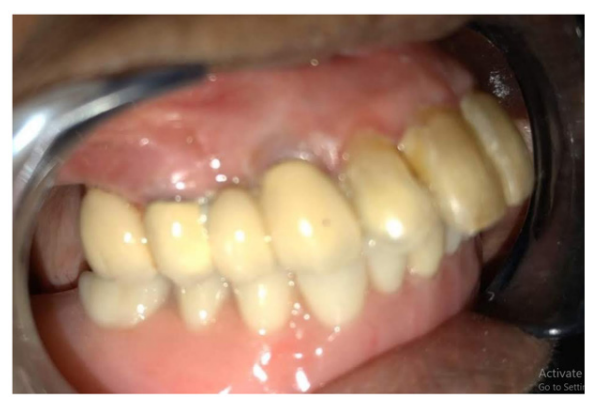

Figure 18: Final Mandibular Prosthesis-Patient Right Lateral.

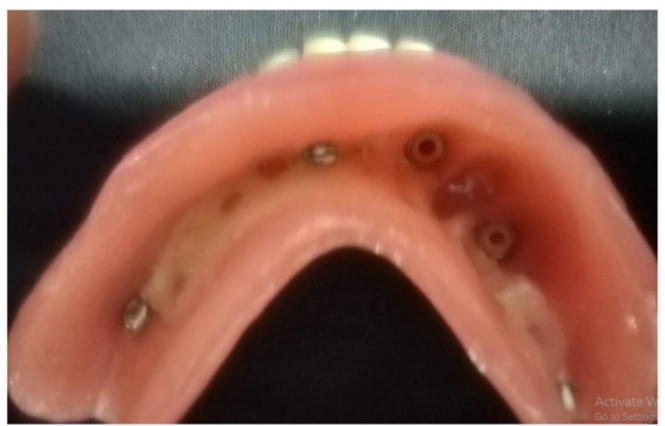

Figure 19: Mandibular Prosthesis-Intaglio Surface.

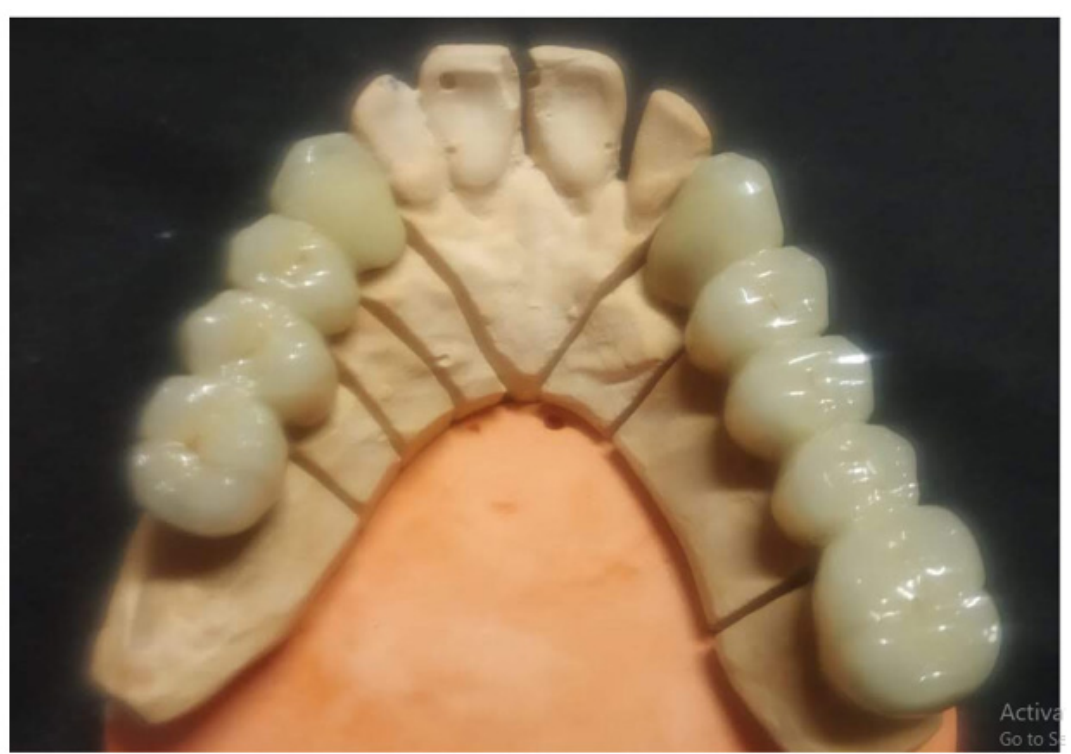

Figure 20: Maxillary Fixed Dental Prosthesis. 


\section{Discussion}

Trends have changed from patient need to replace missing teeth with prosthesis, to a more preferable one where the restoration will be fixed one. In view of patient terms, the term fixed mainly indicates retention $[8,9]$. Considering the fixed treatment options in edentulous areas without distal abutment not only includes implant retained restoration but also a combined prosthesis with a precision attachment [10-12]. Introduction of CAD CAM in dentistry enables the production of various precision and semi precision attachments [13,14] Using these attachments for the purpose of retention in the prosthesis enhances retention, distributes the stress evenly in terms of function, improves esthetics by hiding the metal components as a part of it, supports and preserves adjacent teeth and alveolar bone. Thus, it helps to overcome the challenge in case of terminal edentulous areas and fulfills the patient desire and comfort [15-17].

Various cases with esthetic and retention challenges can be solved with correct selection of Attachment. Rhein 83 attachments used here are most commonly indicated for long edentulous span, distal extension bases and non-parellel abutments $[17,18]$. Combined prosthesis option should follow obtaining thorough knowledge, proper case selection, selection of appropriate attachment and prosthesis design. Patient should also be educated about proper hygiene and maintenance [18]

\section{Conclusion}

Prosthodontic treatment aims to restore the missing dentition but whatever is the trend, prosthetics should also take care of preservation of existing anatomy. Attachments have an important role to play, by way of preventive prosthodontics that revolves around health, function or esthetics, and have the capacity to impact patients in life changing ways. Availing support from the remaining terminal dentition will help in maintaining proper proprioception, better retention and preservation of healthy supporting structures. Thus, in patients with terminal dentition fixed removable precision attachment over dentures with properly selected attachments will boost patient's confidence, comfort, security and will provide very much satisfied results [19]

\section{ORCID}

0000-0003-4466-5744

\section{Acknowledgement}

None.

\section{Conflict of Interest}

No conflict of interest.

\section{References}

1. Naveen Gupta, Abhilasha Bhasin, Parul Gupta, Pankaj Malhotra (2013) Combined Prosthesis with Extra coronal Castable Precision Attachments, Case Rep Dent 2013: 282617; 1-5.

2. HW Preiskel (1985) Precision Attachments in Prosthodontics: Overdentures and Telescopic Prostheses, 2, Quintessence Publishing, Chicago Ill, USA.

3. Applegate OC (1955) The partial denture base. J Prosthet Dent 5: 636645.

4. Stanley F Lorencki (1969) Planning precision attachment restorations, Removable Partial Dentures 21(5): 506-568.

5. Pramod Kumar AV, Vinni TK, Mahesh MR (2012) Full Mouth Rehabilitation with Maxillary Tooth Supported and Mandibular Tooth and Implant Supported Combination Prostheses: A 4 Year Case Report. J Indian Prosthodont Soc 12(2): 113-119.

6. Romesh Soni, Himanshi, Yadav, Aditi, Priya (2018) Combined prosthesis with precision attachment for distal extension kennedy class ii arch: a case report. Ind Jour Sci Res 20: 126-128.

7. Prafulla Thumati (2016) Precision attachment options in Prosthodontic treatment protocols-A series of case reports 13(1): 35-41.

8. Vaidya S, Kapoor C, Bakshi Y, Bhalla S (2015) Achieving an esthetic smile with fixed and removal prosthesis using extra coronal castable precision attachments J Indian Prosthodont Soc 15(3): 284-288.

9. Jayasree Komala, Bharathi Munagapati, Vinnakota Dileep, Bandela Vinod (2012) Precision Attachment: Retained Overdenture. J Indian Prosthodont Soc 12: 59-62.

10. Feinberg E (2011) Precision attachment case restoration with implant abutments: a review with case reports. J Oral Implantol 37(4): 489-498.

11. Kukunoor (2012) A Viable Treatment Alternative in Distal Extension Cases: A Case Report. J Indian Prosthodont Soc 14: 177-180.

12. Yen-Chen Ku, Yu Fu Shen, Chiu-Po Chan (2000) Extra coronal resilient attachments in distal-extension removable partial dentures. Quint Intll 31(5): 311-317.

13. Willium RJ, Bibb R, Eggbeer D, Collis J (2006) Use of CAD/CAM technology to fabricate a removable partial denture framework. J Prosthet Dent 96(2): 96-99.

14. Jumber JF (1981) An Atlas of Overdentures and Attachments', Chicago, Quintessence Publication Co, 1981. (retention)

15. Charkawi HG, Wakad MT (1996) Effect of splinting on load distribution of extra coronal attachment with distal extension prosthesis in Vitro. J Prosthet Dent 76(3): 315-320.

16. Holst S, Blatz MB, Eitner S, Wichmann M (2006) In Vitro wear of different material combinations of intra coronal precision attachments. Int J Prosthodont 19(4): 330-332.

17. Merrill C Mensor JR (1973) Classification and selection of attachments. J Prosthet Dent 29(5): 494-497.

18. Gupta N, Bhasin A., Gupta P, Malhotra P (2013) Combined prosthesis with extra coronal castable precision attachments. Case Rep Dent 282617.

19. Dable RA, Gaikwad BS, Marathe SS, Badgujar MS, Dole VR (2013) A simplified technique for custom made overdenture semi-precision attachments. Indian J Dent Res 24: 622-626. 